\title{
Voces silenciadas por la historia: la hechicera Juana García o la obliteración de la afrodescendencia
}

Voices Silenced by History: The Sorceress Juana García or the Obliteration of Afrodescendence

\author{
Silvia Ruiz Tresgallo ${ }^{\text {a }}$ \\ Universidad Autónoma de Querétaro, México \\ ruiztresgallosilvia@gmail.com \\ ORCID: https://orcid.org/0000-0001-8072-3521 \\ Cecilia López Badano \\ Universidad Autónoma de Querétaro, México \\ cecilial@uaq.mx \\ ORCID: https://orcid.org/0000-0002-8911-6813
}

DOI: https://doi.org/10.11144/Javeriana.cl25.vshh

\section{Resumen:}

Este ensayo pretende ahondar en el relato "Un negocio con Juana García", incluido en el capítulo IX de El Carnero. Proponemos que el texto, a través de la representación de la partera Juana y sus hijas, visibiliza la vulnerabilidad ante la ley de las mujeres afrodescendientes en el Nuevo Reino de Granada. Nuestro análisis revela que la etnia de las protagonistas resulta instrumental tanto en la criminalización de sus actividades, relacionadas por los eclesiásticos con la hechicería, como en su expulsión del espacio colonial al que, según las autoridades, no tienen derecho a pertenecer.

Palabras clave: afrodescendencia, género, Freyle, El Carnero, hechicería, colonial.

\section{Abstract:}

This essay intends to explore the story "Un negocio con Juana García” [A Business with Juana García] included in chapter IX of El Carnero. We propose that this text, through the representation of midwife Juana and her daughters, makes visible that Afro-descendant women are legally vulnerable in the New Kingdom of Granada. Our analysis reveals that the ethnicity of the protagonists is instrumental, both in the criminalization of their activities, related by ecclesiastics with sorcery, and in their expulsion from the colonial space to which, according to the authorities, they have no right to belong.

Keywords: Afrodescendence, gender, Freyle, El Carnero, sorcery, colonial.

\section{Introducción}

Nuestro estudio del cuento interpolado "Un negocio con Juana García”, incluido en el capítulo IX de El Carnero, visibiliza la injusticia cometida contra una mujer afrodescendiente, penitenciada y desterrada por la Inquisición bajo acusación de hechicería dentro del primer auto de fe que tuvo lugar en el Nuevo Reino de Granada (Colombia, hoy en día) en el año de 1563. Juan Rodríguez Freyle no solo nos acerca al caso de una mujer que, debido a su condición racial y bajo estatus social, hubiese sido olvidado por la historia, sino que le permite utilizar su propia voz para acusar a los verdaderos culpables, aunque sea a través de una fusión entre realidad y ficción. ${ }^{1}$ Según los estudios de María Antonia Garcés, "este caso jurídico revela cómo el código del honor aliado con los círculos de poder, así como los prejuicios raciales, controlaban el estatus social e incluso corrompían los procesos eclesiásticos durante la Colonia espan\#ola” (31). Mucho se ha dicho de este caso desde el punto de vista literario e histórico, ya que, como bien lo señala la crítica, ambos discursos resultan manipulados por el autor para realizar un cuadro de costumbres de la sociedad santafereña no exento de tintes escandalosos. Proponemos que el relato de Rodríguez Freyle expone la precariedad ante la ley de las mujeres

Notas de autor

\footnotetext{
a Autora de correspondencia. Correo electrónico: ruiztresgallosilvia@gmail.com
} 
afrodescendientes, las cuales funcionan como chivos expiatorios de sus clientes, la elite de la sociedad colonial marcada por una vida de excesos e impunidad.

Este ensayo propone el análisis de un texto colonial a partir de la crítica actual, que toma como referencia los estudios de género desde una perspectiva interseccional (Crenshaw). Aunque esta área teórica se ha desarrollado especialmente durante los siglos XX y XXI, amparada en especial por el pensamiento feminista, consideramos que sus categorías de análisis resultan a todas luces pertinentes y, por qué no decirlo, clarificadoras para el ensayo que nos ocupa. Si bien en este artículo usamos la definición de un término perteneciente al análisis desde la perspectiva de género en una situación, acto o representación existente en un texto colonial, consideramos que su aplicación es pertinente, ya que esta mirada crítica desde el presente contribuye a dar luz y, por tanto, proporciona una comprensión más profunda del pasado.

\section{Resumen de "Un negocio con Juana García”}

Acudamos a un resumen de los eventos para acercarnos de forma más inmediata a este caso. Una joven, cuyo esposo se encuentra ausente tras su partida con la flota desde Cartagena de Indias, decide aprovechar sus años de lozanía y mantener relaciones con otro varón. Fruto de estos amores ilícitos, ella queda encinta y teme que su marido regrese durante el embarazo y descubra la infidelidad, evento que tendría nefastas consecuencias tanto para la dama como para su vástago. Presa de angustia, acude a la negra Juana García, una conocida partera con fama de hechicera, quien, para prevenir un remedio, organiza una cena con varias mujeres, entre las que se encuentran sus hijas y la clienta. Durante el convivio, la paciente y Juana se reúnen en un cuarto aparte, donde, por medio del reflejo del agua en un lebrillo verde, usado como si fuera una bola de cristal, la esposa puede ver lo que está haciendo su marido. De acuerdo con el testimonio de la dama, su señor también parece ser infiel, pues acompaña a una mujer, a quien un sastre le está confeccionando un vestido de color grana, dándonos a entender que ese es el pago por sus encuentros ilícitos. La nigromante, quien desvela que el esposo se halla en la isla Española de Santo Domingo, toma un trozo de la manga del traje que está en proceso de confección y se lo entrega a la clienta como prueba. Juana deduce que tanto las ocupaciones del marido como su distancia del reino le permitirán a la joven dar a luz a su hijo ilegítimo sin miedo a ser sorprendida. Cuando el esposo de la señora vuelve tras un largo periodo de ausencia, esta le reprocha su infidelidad y le muestra como prueba la manga del traje que Juana le entregó. Indignado, el marido denuncia a la partera ante el juez inquisidor, pero las confesiones de Juana García implican a personas principales que, ante el miedo de ser expuestas y condenadas, interceden para que la pena sea leve. Sin embargo, quienes sí sufrirán las consecuencias de esta volatería son Juana y sus hijas: la negra hora padece una penitencia pública y, junto con sus descendientes, será desterrada del reino. En la memoria de la comunidad, el cerro en el que según los locales la supuesta hechicera voló pasa a denominarse como cerro de Juana García.

\section{Acercamiento teórico y crítico: Juana García como chivo expiatorio}

En su libro Le bouc émissaire [El chivo expiatorio] (1982), el intelectual francés René Girard formula una teoría inspirada en el poder mimético de la violencia. Según el antropólogo, los seres humanos, a través de un acto de imitación, desean poseer los mismos objetos o seres, los cuales son limitados, motivo por el que se podría desencadenar un conflicto que causaría enfrentamientos violentos e incluso asesinatos entre los miembros de una sociedad. El poder desintegrador de este tipo de violencia sería enorme. Entonces, para mantener el orden y evitar una crisis que pondría en peligro la estabilidad social, las comunidades antiguas creaban una amenaza común que permitía unificar a sus miembros. Al elegir a un chivo expiatorio, se lograba encarnar en un individuo o en un grupo específico de individuos ese peligro que se debía extirpar y/o destruir; de este 
modo, la unión de una comunidad, más o menos imaginada, se afianzaba, al mismo tiempo que se desplazaba la violencia hacia una víctima sacrificial; este es, precisamente, el caso que nos ocupa en este ensayo.

Proponemos que, en la anécdota de Rodríguez Freyle, Juana García funciona como un chivo expiatorio, es decir, se constituye en una víctima propiciatoria de la sociedad colonial del Nuevo Reino de Granada. En su libro, Girard señala: "Cuantos más signos de una víctima tenga un individuo, mayor será la probabilidad de atraer desastres" (26; traducción realizada por Silvia Ruiz Tresgallo). Cabe preguntarse, entonces, cuáles son los signos que identifican a Juana, y con ella a sus descendientes, como las víctimas ideales. Para comprender cuáles son las categorías que proponen a estas mujeres como un peligro que hay que eliminar en la Santafé de Bogotá colonial, debemos acercarnos a las teorías de Judith Butler sobre la precariedad de la vida y su relación con las acusadas ante el Santo Oficio de la Inquisición.

\section{Cuerpos precarios: género, etnia e inquisición}

En su libro Precarious Life [Vida precaria] (2004), Judith Butler define qué tipo de cuerpos resultan más vulnerables y, por tanto, susceptibles de recibir violencia. Aunque todas las personas presentan una cierta fragilidad, debido a la finitud de la propia condición humana, no todas ven su existencia comprometida al mismo grado. De hecho, las agresiones que reciben determinados cuerpos en una sociedad se deben a su pertenencia a minorías que no cumplen con las "nociones normativas de lo humano" (Butler 59). La etnia, "dado el carácter racial que sostiene las nociones culturalmente viables de lo humano que vemos actuar de modo dramático y terrorífico en el mundo" (Butler 59), además del género y la sexualidad, entre otras características, crean una morfología que condena o borra a determinados colectivos. Entendemos entonces que cuantas más categorías de precariedad atraviesen la materialidad de los cuerpos, más probabilidades tienen de ser perseguidos, atacados y/o exterminados. A través del análisis de las denuncias inquisitoriales, así como de la suma de situaciones de vulnerabilidad en los acusados, podemos observar qué cuerpos "no importan" (Butler) en la sociedad colonial.

En su estudio previo sobre las condiciones de precariedad que facilitaban las denuncias ante el Santo Oficio, Silvia Ruiz Tresgallo ha propuesto algunos signos. El primer elemento es el género, puesto que ser mujer supone pertenecer a una categoría inferior a la del varón. La etnia es el segundo aspecto a tener en cuenta, ya que, cuanto más alejado esté un individuo del modelo caucásico peninsular, más posibilidades tiene de ser perseguido. Nos referimos aquí a las afrodescendientes (negras, mulatas), mestizas, etc. El tercer elemento es el estado civil, ya que, para una mujer, estar soltera o viuda significaba no solo no cumplir con su papel reproductivo, sino no ser controlada por el esposo. Por supuesto, la clase social y la filiación resultan muy importantes en la sociedad colonial, ya que, en muchos casos, las esclavas y criadas se adscribían a sus amos, y por tanto al rancio abolengo de quienes las contrataban para justificar que, como sus señores, eran buenas cristianas, y no discípulas de Satán. La última condición que incluimos es el nivel económico, porque tanto si este es bajo como si las actividades lucrativas le permiten a una mujer ser autónoma, la fémina es más susceptible de ser acusada. Es decir, la pobreza, que dificulta la subsistencia y la independencia económica, que elude la supervisión masculina, colocan a las damas en una situación de precariedad (Voces silenciadas s. p.).

De acuerdo con esta clasificación, Juana y sus hijas se constituyen en chivos expiatorios porque cumplen varias categorías que las hacen más susceptibles de recibir violencia. Entre los elementos que las marcan se destacan dos: su género - puesto que los inquisidores consideraban que las mujeres eran más débiles a los influjos del demonio- y la etnia de los cuerpos que habitan — unida desde la voz del colonizador con los adoradores de Satán-. En este sentido, la intersección entre género y etnia que atraviesa el cuerpo de nuestra protagonista resulta clave para que la acusación prospere, como lo demuestran los procesos de la época; Juana es una mujer afrodescendiente que ha sido esclava y ahora vive en libertad, ${ }^{2}$ todos elementos asociados a las inculpadas en los tribunales coloniales de la Inquisición, en especial en el Nuevo Reino de Granada y la 
zona del Caribe. Además, se dedica al oficio de partera y practica la magia adivinatoria, actividades que las autoridades criminalizan al considerarlas, por la influencia de los inquisidores, como actos demoniacos. Es necesario tener en cuenta que las mujeres pobres que no dependían económicamente de un varón tenían un número de oficios limitados dentro de la sociedad colonial para poder autofinanciarse, siendo la labor de comadrona una de las pocas disponibles. También, los eclesiásticos relacionan la hechicería con las prácticas sexuales fuera del matrimonio, motivo por el que la actividad de las hijas como prostitutas y la supuesta alcahuetería de la madre son consideradas como parte del delito de brujería. Por supuesto, los signos de la víctima propiciatoria se intensifican en el relato, porque tanto Juana como sus descendientes son mujeres autónomas, subsisten a través de su propia autofinanciación y en ningún momento se indica que estén casadas o bajo la supervisión de algún familiar varón. En este sentido, este cuento intercalado nos acerca a la vida de las mujeres en situación de precariedad; las perseguidas de la historia.

\section{Las parteras: protectoras de la vida y guardianas del cuidado del cuerpo femenino}

Recordemos que, dentro del relato de Rodríguez Freyle, Juana García resulta aludida en numerosas ocasiones con la palabra "comadre" (119) uno de cuyos significados es el de 'partera o matrona', aspecto que resulta de utilidad en nuestro análisis, ya que sabemos entonces que se encarga no solo de los abortos de sus clientas, sino también de los partos y el cuidado de los bebés. Sebastián de Covarrubias define este término como una práctica de protección femenina al escribir: "Vale madre, juntamente con la que lo es verdadera; y llamamos comadre a la que ayuda a parir, que cura de la madre y de la criatura. E\#sta por otro nombre se llama partera”. Por supuesto, Juana García, de acuerdo con su labor de matrona, debe salvaguardar la salud de su clienta, la cual se vería gravemente comprometida si su esposo la encontrara embarazada tras una ausencia de tantos meses. Dada la imbricación de la violencia con los afectos heteronormativos dentro de la sociedad colonial que refleja El Carnero, tanto la dama como su hijo podrían haber sido asesinados por el marido sin recibir por ello reprobación o castigo, ya que este acto hubiese sido interpretado como el derecho del varón a limpiar su honor. De hecho, dentro del relato, la negra horra preserva la vida, puesto que averigua que el esposo de la hermosa dama no ha arribado con la flota a Cartagena de Indias, motivo por el que no es necesario que la joven aborte a la criatura, sino que podrá dar a luz a su vástago e incluso lo criará en su casa con nombre de huérfano.

Como lo demuestran los estudios de Silvia Federici, con el inicio de la modernidad en Europa, la Inquisición busca la eliminación de las matronas para controlar los cuerpos de las mujeres. En una sociedad patriarcal, el único valor del cuerpo femenino es el de la reproducción, por lo tanto, todas las prácticas que no tengan comofinalidad este objetivo - por ejemplo, el aborto o los métodos contraceptivos que hasta entonces se habían realizado sin penalización- sufrirán una demonización. Los médicos titulados en la universidad sustituirán a las parteras y despojarán durante siglos a las mujeres del conocimiento de su sexualidad. En opinión de esta intelectual:

Con la marginación de la partera, comenzó un proceso por el cual las mujeres perdieron el control que habían ejercido sobre la procreación, reducidas a un papel pasivo en el parto, mientras que los médicos hombres comenzaron a ser considerados como los verdaderos "dadores de vida". (Federici 137)

Aunque en el caso del continente americano existen diferencias en este proceso, debido principalmente al régimen especial de los pueblos originarios, la mujer perseguida en este ensayo, al ser afrodescendiente, no estaba protegida por esas leyes, motivo por el que podía ser juzgada por la Inquisición. No hay duda de que este cuento interpolado de Rodríguez Freyle refleja, a través de su protagonista, la continuidad de la demonización de las matronas en el espacio colonial por parte de las autoridades eclesiásticas. 
Prueba de la similitud entre el trabajo de una partera y un médico en El Carnero son las palabras que emplea la esposa embarazada cuando acude a Juana García, a quién consulta como si de un galeno se tratara. En concreto, le dice: "Mucho me duele la barriga: ¿queréis vérmela?" (120). Sobre este tema, Hortensia Calvo y José Piedra proponen que "el autor matiza científicamente la brujería al punto que no resulta distinguible de las prácticas médicas de esa época” (110; resaltado del original). Además, con frecuencia las parteras y sanadoras llevaban a cabo rituales de magia blanca, que poco o nada tenían que ver con un pacto con el demonio, sino que más bien resultaban prácticas comunes en la vida cotidiana. En especial, al situarnos en una sociedad basada en la dependencia de la mujer con respecto al hombre, los conjuros para hallar al esposo ideal, mantener una buena relación con él y/o averiguar su paradero están a la orden del día.

\section{Rituales de magia blanca: "La suerte del agua"}

El uso de un recipiente con agua para encontrar a una persona ausente, generalmente maridos desaparecidos, era una suerte común reportada tanto en España como en la América del siglo XVII. Acudamos al ritual que protagonizan Juana y su clienta en El Carnero:

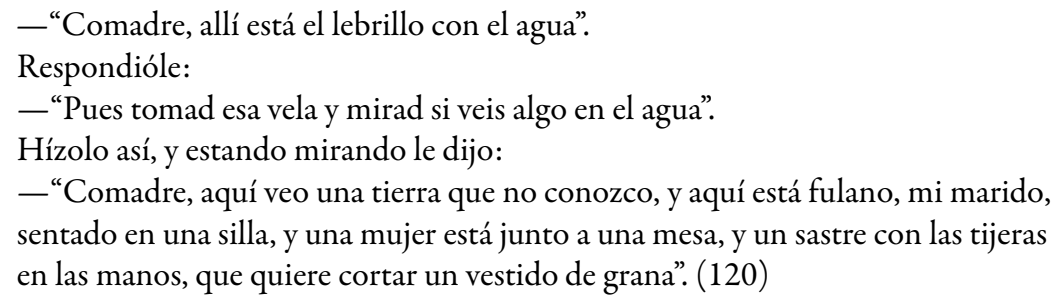

Resulta evidente que el objetivo del sortilegio es localizar al esposo de la dama en cuestión, acción que no solo se logra, sino que expone sus actividades ilícitas. Por ejemplo, un conjuro similar al de Juana García se recoge en los archivos de la Inquisición del virreinato de la Nueva España, donde, según los datos recopilados por María Águeda Méndez, la "India Mariana de Nevado, por medio de una redoma llena de agua a la que le echo un huevo veía que les había sucedido a personas ausentes" (476). Prueba de que este ritual tenía sus antecedes europeos es el hecho de que un procedimiento similar se reporta en España, en concreto, en el caso de la gitana María Hernández, acusada ante la Inquisición en 1635, según lo recoge Julio Caro Baroja ${ }^{3}$. Quizás, lo que resulta más curioso de estas coincidencias transamericanas y transatlánticas es que las mujeres acusadas ante la Inquisición pertenecen a los grupos étnicos discriminados por la sociedad de la época, aspecto que evidencia no solo la demanda cotidiana de estos servicios por parte de las mujeres pertenecientes a la élite, sino también que son las supuestas hechiceras y no las clientas, en especial cuando se alejan del ideal caucásico, quiénes resultan más vulnerables ante la ley.

Como va resultando evidente, los conjuros que practica Juana García a través del lebrillo de agua no tienen mayor objetivo que el de cuidar la salud de su clienta e incluso salvaguardar la vida de su hijo. Prueba de este deseo sanador es que la matrona aconseja a la esposa no interrumpir su embarazo al afirmar: "Ya habéis visto cuán despacio está vuestro marido, pues podéis despedir esa barriga, y aún hacer otra” (121).

\section{Sororidad interracial}

El autor de El Carnero nos hace presenciar una sororidad interracial, ya que establece relaciones rizomáticas (Deleuze y Guattari) entre damas de distinta etnia y condición, para proporcionar un cuidado femenino. Recordemos que la reunión nocturna en la que Juana realiza el sortilegio viene precedida de un jolgorio con comida, cante y baile - del que participan no solo las implicadas en el sortilegio, sino también "mozas 
vecinas" (120). De hecho, son precisamente los miembros de la élite masculina, el esposo infiel y el juez inquisidor, los que rompen esta red de apoyo entre mujeres por medio de la acusación de hechicería.

\section{Juana García y las inculpadas por hechicería en el Nuevo Reino de Granada}

El género, la etnia y la facultad voladora de la protagonista de "Un negocio con Juana García” sugieren que Rodríguez Freyle escribe su relato influido por las inculpadas de brujería en el Nuevo Reino de Granada. Los estudios de Jaime Humberto Borja Gómez y Anna María Splendiani, ${ }^{4}$ entre otros investigadores, confirman la presencia abundante de afrodescendientes en las denuncias de los siglos XVI y XVII. Borja señala que "los españoles tenían miedo de los poderes sobrenaturales de los negros, como lo demostró la proliferación de acusados por ejercer brujería, herbolería o hechicería con fines amatorios" (182). Dentro de los imputados, la mayor parte son mujeres negras y mulatas, en especial en el famoso caso de las brujas de Tolú (1632), persecución masiva que tuvo lugar en este puerto de mar situado a más de 100 kilómetros de Cartagena. ${ }^{5}$ Proponemos que Rodríguez Freyle nos habla del pasado, en concreto del auto de fe de 1563, pero influido por un presente en que las mujeres afrodescendientes eran acusadas de volar con el diablo o bailar con él en la figura de un macho cabrío, como sucede en el caso de Tolú. La evidente falsedad de estas denuncias fantásticas, que ya habían recibido numerosas mujeres en Europa, muestra que en el Nuevo Reino de Granada la intersección entre género y etnia señala claramente a las afrodescendientes como las víctimas propiciatorias de la sociedad colonial. A diferencia de estos investigadores, no consideramos que la población negra o mulata tuviera una atracción especial por la hechicería, sino que más bien, y este es el punto que nos interesa, ellas se convertían en las castas más vulnerables y susceptibles de recibir denuncias ante la Inquisición. Recordemos que tanto el uso de la magia blanca como el oficio de partera forman parte de una tradición de cuidado femenino que ha pasado de generación en generación y que poco a nada tiene que ver con un pacto con el diablo. Además, en general, los hombres blancos preferían el concubinato con negras y mulatas, y no el matrimonio, motivo por el que las ilusiones de inclusión social de muchas de estas mujeres quedaban truncadas. 


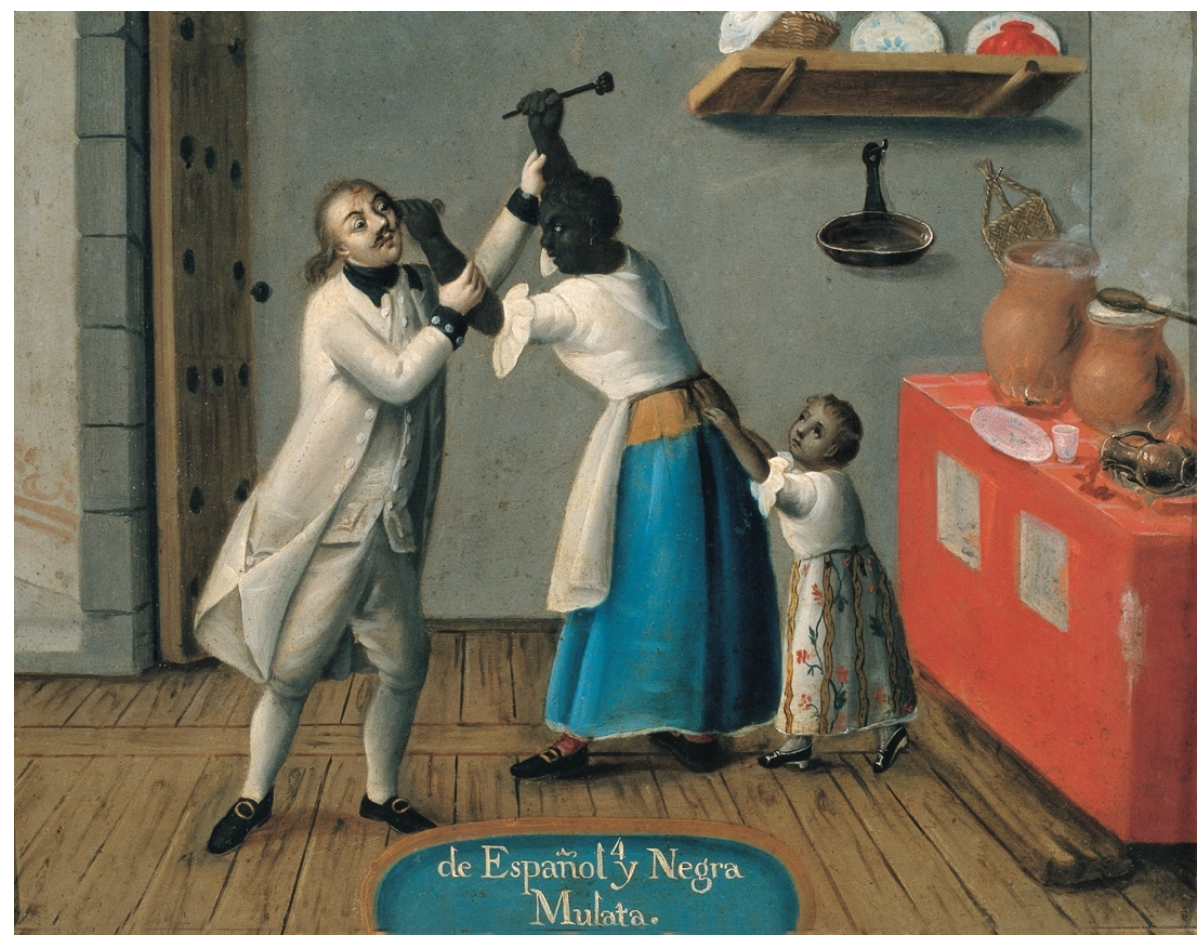

FIGURA 1.

Autor novohispano anónimo, De español y negra, mulata. 1775-1800

Fuente: Museo de las Américas, Madrid. Fotografiado por Joaquín Otero Úbeda.

La imagen De español y negra: mulata (1775-1800) (Figura1), perteneciente a la llamada pintura de castas, funciona a modo de propaganda para indicar las consecuencias que tendría para un varón español casarse con una mujer de esta etnia. Sin duda, la actitud violenta de la afrodescendiente hacia su esposo, a quien, según los modelos propuestos en la época, debiera respetar, junto con su representación en el espacio normalmente asignado al servicio, la cocina, no auguran un futuro próspero ni para el marido ni para su heredera. Al observar esta representación, cuya manipulación resulta notoria, no podemos dejar de pensar en las imágenes más probables dentro de la realidad histórica que curiosamente forman parte de un archivo invisible, puesto que brillan por su ausencia; nos referimos a pinturas que muestren a las afrodescendientes explotadas física y/o sexualmente por sus amos o empleadores. A pesar de que el ejercicio de la violencia contra las mujeres de esta etnia era común durante la colonia, el statu quo manipula el discurso para depositar en el cuerpo de las afrodescendientes el peso de la agresión y, de esta manera, justificar su posición periférica. Sorprende observar que Juana y sus hijas son culpabilizadas por no estar casadas, cuando en realidad son los varones de la colonia los que, de acuerdo con los ideales de la época, no desean contraer nupcias con ellas.

\section{Sociedad en crisis: acusación de las masculinidades hegemónicas coloniales y visibilización de las marginadas de la historia}

Girard, dentro de los estereotipos propios de la persecución de víctimas propiciatorias, escoge una sociedad en crisis (14), justo la situación que desencadena la imputación de Juana García. Recordemos que el escándalo se forma cuando el marido de la malcasada descubre la manga del vestido de su amante y acude al juez inquisidor. Aunque durante el cuestionamiento al que se somete a Juana se dice que las mujeres son sus clientas, resulta evidente que también los caballeros más insignes se encuentran entre los que contratan sus servicios. Prueba de ello es que, cuando el juez inquisidor va a condenar tanto a la sanadora como a sus asiduos 
feligreses, las masculinidades hegemónicas (Connell y Messerschmidt) del reino interceden por una solución que asegure dos puntos: ocultar el nombre de los acusados e impedir el derramamiento de sangre. Como expresa Rodríguez Freyle:

Depuso de otras muchas mujeres [...]. Corrió la voz de que eran muchos los que habían caído en la red, y tocaba a personas principales. En fin, el Adelantado don Gonzalo Jiménez de Quesada, el capitán Zorro, el capitán Céspedes, Juan Tafur, Juan Ruiz de Orejuela y otras personas principales acudieron al señor obispo. (123; énfasis propio)

Si analizamos la construcción lingüística del texto, la expresión personas principales se utiliza tanto para hablar de aquellos que contratan los servicios de Juana como para aludir a la élite varonil que aboga por el perdón, aspecto que sugiere que ambos grupos están constituidos por los mismos individuos. Como se insinúa en esta cita, y como veremos más adelante a través de la voz de Juana, Rodríguez Freyle demoniza y feminiza a la élite colonial. Estos hombres se comportan como supuestamente lo hacen las mujeres de El Carnero, es decir, mal, y quedan impunes por unos delitos contra la moral cristiana que ellos mismos comenten, pero que solo pagará la sanadora, el chivo expiatorio de la historia. ${ }^{6}$

\section{El castigo público de Juana: la obliteración de la afrodescendencia}

La vergüenza pública que recibe Juana García corresponde a la pena por delito de hechicería con destierro en el Nuevo Reino de Granada. Según Rodríguez Freyle: "Su Señoría ... topó sólo con Juana García, que la penitenciaron poniéndola en Santo Domingo, a horas de la misa mayor, en un tablado, con un dogal al cuello y una vela encendida en la mano" (123). En el libro 1 dedicado a los Cincuenta años de Inquisición en el Tribunal de Cartagena de Indias, Splendiani especifica que los signos de infamia eran "símbolos u objetos alusivos a la falta cometida que el condenado debía llevar en público, en forma temporal o permanente, para que todos conocieran el delito que había cometido" (54). Al revisar casos similares, podemos comprobar que la penitencia que recibe la protagonista, denominada "En cuerpo con vela en la mano", era habitual en el reino para casos de personas acusadas de hechicería y condenadas con pena de destierro. ${ }^{7}$ A su vez, el castigo de la afrodescendiente continúa en el continente americano las violencias que sufrieron injustamente las mujeres condenadas por brujería en el Viejo Mundo. 


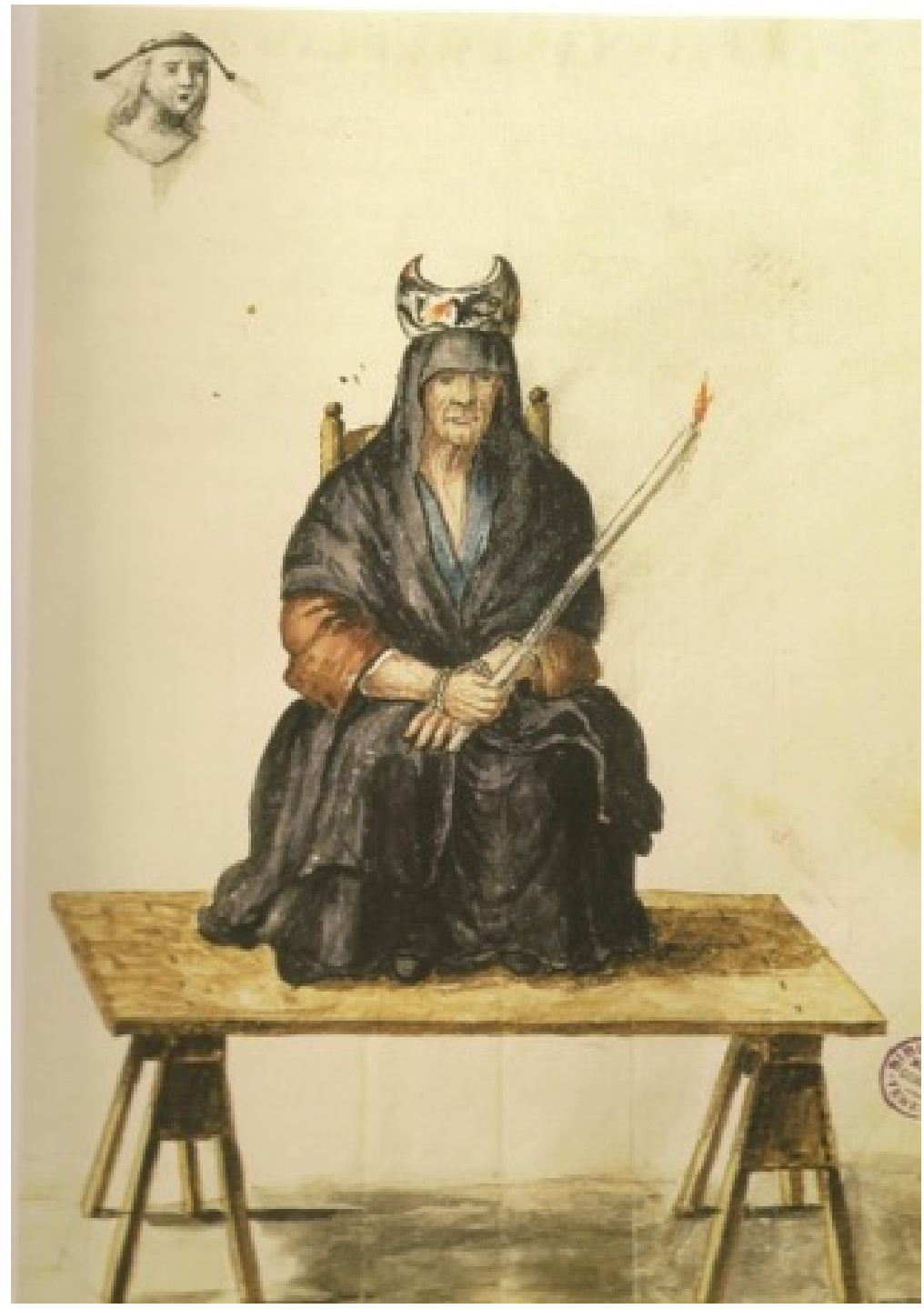

FIGURA 2.

Punishment of a Sorceress, Grevenbroeck II, Jan van (1731-1807).

Carboncillo, tinta y acuarela sobre papel. Museo Correr, Venecia, Italia Fuente: Robert Muchembled (108).

La imagen del castigo de Juana tiene ciertas similitudes con la que Jan van Grevenbroeck II (1731-1807), en Punishment of a sorceress [Castigo de una hechicera] (Figura 2), presenta en el territorio europeo. En este carboncillo, una mujer de avanzada edad está colocada en un tablado y sostiene en sus manos una vela, de modo semejante a la negra horra en la descripción de Rodríguez Freyle. Según Robert Muchembled, esta mujer europea corresponde a los estereotipos rurales del mundo mediterráneo sobre la baja posición social de las hechiceras (108). En opinión de Muchembled, la nigromante de van Grevenbroeck porta los símbolos satánicos en su gorro con forma de cuernos, para permitirles a los espectadores comprender que la fuente de su castigo es ser una mala cristiana. Su escarmiento la marca como rebelde, o al menos indica que no es una mujer sumisa (108). Una diferencia con respecto a esta imagen de la hechicera europea es que, en el relato del autor neogranadino, Juana no porta cuernos en su cabeza, sino que lleva un "dogal al cuello" (123), un castigo usual para ahorcamientos y otros suplicios. Para el lector de la colonia, al ser una mujer negra la penitenciada con el dogal, esta imagen evoca otros escenarios vinculados con el bagaje étnico de la protagonista; nos referimos a la memoria de los mercados de esclavos, en los que las personas afrodescendientes iban amarradas al cuello 
con sogas y también eran presentadas para su venta pública sobre tablados. Las autoridades administran este castigo a Juana por practicar la hechicería y con este acto, de forma voluntaria o involuntaria, la devuelven de modo simbólico al estado de esclavitud.

\section{Juana García y los africanos voladores}

Si nos atenemos al mito caribeño de los africanos voladores, Rodríguez Freyle, al afirmar que Juana voló desde el cerro que está detrás de Nuestra Señora de las Nieves, nos podría estar indicando el lugar donde fue asesinada. Según Roberto González Echevarría, este cuento interpolado de Rodríguez Freyle contiene elementos de la tradición del africano volador que, tras su muerte, asciende al cielo y regresa a su continente originario (50). Dentro de su confesión, el narrador indica que Juana "se echó a volar desde el cerro que está a las espaldas de Nuestra Señora de las Nieves, donde está una de las cruces; y después, mucho tiempo adelante, le llamaban Juana García, o el cerro de Juana García” (124). Si leemos el relato que nos ocupa desde el mito caribeño de los africanos voladores, podríamos pensar que este lugar geográfico, marcado además con una cruz, como las tumbas o los cementerios, indicaría el espacio donde no solo Juana, sino también sus hijas "volaron" de una manera literal; es decir, fueron empujadas, asesinadas y posteriormente enterradas. Recordemos que estas mujeres conocían los secretos de gran parte de la élite colonial de Santafé de Bogotá y que, por tanto, convenía que sus voces fueran acalladas para siempre.

En otra línea de pensamiento, debemos recordar que la capacidad de volar, de acuerdo con las declaraciones altamente cuestionables recogidas por el Santo Oficio, se utiliza para justificar no solo la imputación de hechicería, sino también el subsiguiente castigo de destierro y por tanto la eliminación sistemática de mujeres afrodescendientes del Nuevo Reino de Granada. Los estudios de Juan Blázquez Miguel señalan que, además de la confiscación de bienes y los azotes, el destierro era una de las penas comunes que recibieron las imputadas en Cartagena de Indias, en su mayoría negras y mulatas (74). Va resultando evidente que Lucifer viaja al continente americano en las mentes de los conquistadores y colonizadores, quienes practican el sacrifico de las mismas poblaciones perseguidas en la península, pero adaptadas a las circunstancias específicas del entorno americano.

\section{Eliminación simbólica de la afrodescendencia en el espacio colonial}

Con el destierro de Juana y sus hijas, Rodríguez Freyle expone la eliminación simbólica de la afrodescendencia en el espacio colonial. Las mujeres de esta etnia, en general, no tienen cabida en la identidad social neogranadina y, si la tienen, es eminentemente periférica. La negra y sus descendientes se integran en una historia infame que demoniza, excluye e invisibiliza a la población afrodescendiente en el territorio americano. Como vemos en esta narración, se trunca en las mujeres de esta etnia la capacidad de reproducirse de una manera efectiva, ya que, cuando lo hacen, como es el caso de Juana que tiene a sus hijas, se expulsa a su descendencia, causando así una exclusión de su progenie. Tanto Juana como su familia desaparecen de la identidad neogranadina sin dejar tras de sí un legado genético y/o cultural de valor. Aquellos santafereños que no desean la mezcla étnica con la población afrodescendiente pueden congratularse, ya que, gracias a esta narración, no quedarán rastros de la presencia de estas damas; solo permanecerá la leyenda infame que justifica su expulsión del reino por sus faltas contra la fe.

En este contexto, las palabras de Juana “iTodas, todas lo hicimos y yo sólo lo pago!” (123), exclamadas mientras la penitencian en Santo Domingo a la hora de la misa mayor, suponen un grito de resistencia que no solo acusa a las masculinidades hegemónicas del reino, sino que también señala a los culpables de las violencias recibidas por miles de mujeres en la historia. Como delata nuestro estudio, son los jueces, conquistadores, encomenderos, eclesiásticos, altos cargos, es decir, los varones con poder, los que durante la modernidad 
temprana han acusado a las mujeres por el ejercicio de la hechicería, en el caso de El Carnero, para ocultar sus propias faltas. La hembra, tradicionalmente configurada por el patriarcado como un cuerpo sin voz, al menos en el relato del neogranadino tiene la oportunidad de expresarse para denunciar a sus verdugos y con ello unirse al grito de miles de mujeres silenciadas. Hablamos aquí en especial de las injusticias cometidas contra las damas acusadas y condenadas por la Inquisición, muchos de cuyos testimonios permanecen aún olvidados, enterrados en los archivos, a la espera de ser escuchados e interpretados desde una perspectiva de género que incluya además un giro interseccional.

Llegados a este punto, cabe preguntarse si el autor, al exponer este caso, se pone del lado de Juana y sus hijas, las marginadas de la historia que nos han acompañado durante estas páginas. Por un lado, dentro de $E l$ Carnero predomina una representación negativa de lo femenino que continúa la misma tradición misógina que predicaban los padres de la Iglesia y que refuerza el Malleus Maleficarum del siglo XV, el manual para la persecución de brujas por excelencia (Kramer y Sprenger). Por otro lado, el autor está influido por la tradición picaresca, en la cual la vida de los miserables adquiere centralidad para señalar las injusticias sociales, así como los abusos de los poderosos.

$\mathrm{Al}$ analizar "Un negocio..." en relación con la totalidad de El Carnero, consideramos que el caso de Juana García es utilizado por el autor para visibilizar la corrupción y la parcialidad que los hombres principales promueven en el Nuevo Reino de Granada. Sobre este tema discute Carmen de Mora, quien afirma: "La injusticia, la mentira y la arbitrariedad forman parte de las actuaciones cotidianas de visitadores, presidentes, fiscales y oidores" (100). Recordemos que la única frase que Juana exclama en el texto sirve para denunciar de manera subrepticia las infracciones de estos varones ilustres. Si bien Rodríguez Freyle, a diferencia de las mujeres silenciadas que predominan en su texto, sí le permite a la partera utilizar su voz en un discurso directo, lo cual podríamos interpretar de una manera positiva, esta misma voz está manipulada por el autor para que convenga a sus propios intereses y objetivos edificadores que, en nuestra opinión, no se centran en una defensa de las afrodescendientes. Aunque Rodríguez Freyle presenta el cuento interpolado con guiños humorísticos que generan cierta simpatía hacia estos personajes, no entendemos que su intención sea denunciar las injusticias que padecen, en concreto, una supuesta hechicera y sus hijas prostitutas y aprendices del oficio de encantadora, que sin duda él colocaría dentro del estereotipo de la "mala mujer" que predomina en $E l$ Carnero. En este sentido, tanto el protagonismo que adquieren Juana y sus herederas como la visibilización de las iniquidades que sufren podrían ser efectos no intencionales del autor, pero que, desde la mirada que en el presente nos otorgan los estudios de género, exponen violencias normalizadas en la sociedad colonial de las que probablemente participa el mismo Rodríguez Freyle.

\section{Reflexiones finales}

Durante este ensayo hemos planteado cómo, tanto la acusación de la negra Juana García como su expulsión del Nuevo Reino de Granada junto con sus hijas, supone una condena que pretende borrar la afrodescendencia del espacio colonial. Estas mujeres, debido a su género y a su etnia, poseen una morfología que no entra en la categoría de lo ininteligiblemente humano en la sociedad de la época, aspecto que precariza la materialidad de sus cuerpos al hacerlos más susceptibles de recibir violencias. Prueba de la precariedad de sus vidas es su relación como colectivo con el perfil de las acusadas por las autoridades inquisitoriales del Nuevo Reino de Granada, en su mayoría negras (horras, esclavas) y mulatas, como nuestras protagonistas. El santafereño Rodríguez Freyle expone - a nuestro parecer- de una manera involuntaria lo que las autoras de este artículo interpretamos como la injusticia cometida contra Juana y sus hijas, y, a través de estos personajes, las violencias sufridas por las afrodescendientes silenciadas por la historia.

Nuestro análisis muestra a una mujer autónoma que prioriza la vida, tanto la de su clienta como la de su vástago, siguiendo una genealogía de cuidado y sororidad femeninas que se ha conservado en las comunidades 
afrodescendientes actuales y que, en este caso, funciona como un tipo de resistencia a la vigilancia patriarcal colonial. En esta línea de pensamiento, la criminalización de las matronas, las prostitutas y las mujeres que practican rituales de magia blanca es una decisión de las autoridades eclesiásticas que demonizan estos oficios y con ello justifican la violencia ejercida contra este colectivo. A través de la voz de Juana, se rompe una tradición de silenciamiento de las mujeres afrodescendientes que, al menos en este texto, señalan a los culpables, en especial a los hombres de la élite, quienes, de forma secreta, utilizan sus servicios. Va resultando evidente que la construcción de Juana y sus hijas como los chivos expiatorios del relato indica no solo que las afrodescendientes no tenían un pacto con el diablo, sino más bien que su etnia, pero también otras características que atraviesan sus cuerpos, como su género, su profesión y su autonomía, las hacían más vulnerables ante la ley.

Rodríguez Freyle utiliza en este relato a las marginadas de la historia para condenar la corrupción de los varones ilustres en el Nuevo Reino de Granada, una decisión que usa del cuerpo y la voz de estas mujeres para su propio beneficio y que está alejada, en nuestra opinión, de la denuncia social o la búsqueda de justicia para este colectivo. Sin embargo, este texto, siglos más tarde, les permite a las autoras de este ensayo visibilizar el uso sistemático de la acusación de brujería como método infalible para la eliminación, exclusión e invisibilización de la afrodescendencia en el espacio americano.

\section{Referencias}

Blázquez Miguel, Juan. “Brujas e inquisidores en la América colonial (1569-1820)”. Espacio, Tiempo y Forma, serie IV, Historia Moderna, n. ${ }^{\text {os }}$ 7-1, 1994, pp. 71-98.

Butler, Judith. Vida Precaria. Paido\#s, 2006.

Borja Gómez, Jaime Humberto. “El control sobre la sexualidad: negros e indios (1550-1650)”. Inquisición, muerte y sexualidad en la Nueva Granada, editado por Jaime Humberto Borja Gómez, Ariel, 1996, pp. 171-98.

Calvo, Hortensia y José Piedra. "El Carnero según Juana García: una manga afrofemenina de la historia colombiana”. Dispositio, vol. 18, n. ${ }^{\circ} 44,1993$, pp. 99-124.

Caro Baroja, Julio. Vidas mágicas e Inquisición. Vol. 1, Taurus, 1967.

Channing Eberhard, Carmen. "La intertextualidad en El Carnero de Juan Rodríguez Freyle: escándalo y pecadores en Nueva Granada (1636-1638)”. Intus-Legere: Historia, año 9, n. ${ }^{\circ} 2$, 2015, pp. 39-58.

Connell, R. W. y James W. Messerschmidt. "Hegemonic Masculinity: Rethinking the Concept". Gender \& Society, vol. 19, n. ${ }^{\circ}$ 6, 2005, pp. 829-859.

Covarrubias, Sebastián de. Tesoro de la Lengua Castellana o Española, editado por Martín de Riquer, S. A. Horta, I. E., 1943.

Crenshaw, Kimberlé Williams. "Cartografiando los márgenes: interseccionalidad, políticas identitarias, y violencia contra las mujeres de color". Intersecciones: Cuerpos y sexualidades en la encrucijada: temas contemporáneos, editado por Raquel Platero, 1991, Bellaterra, 2012, pp. 87-122.

De español y negra, mulata. 1775-1800, Museo de las Américas, Madrid. Fotografiado por Joaquín Otero Úbeda. http://ceres.mcu.es/pages/ResultSearch?Museo=MAM\&txtSimpleSearch=Castas\&simpleSear ch=0\&hipertextSearch=1\&search=simple\&MuseumsSearch=MAM\%7C\&MuseumsRolSearch=11\&

Deleuze, Gilles y Félix Guattari. Rizoma: Introducción. Pre-textos, 1977.

Federici, Silvia. Calibán y la bruja. Mujeres, cuerpo y acumulación originaria. Traficantes de sueños, 2010.

Garcés, María Antonia. “Los olvidados de la historia: Juana García y el archivo alternativo de El Carnero”. Revista de estudios colombianos, n. ${ }^{\circ} 35,2009$, pp. 31-44.

Girard, René. The Scapegoat. Johns Hopkins University Press, 1986.

González Echevarría, Roberto, editor. The Oxford Book of Latin American Short Stories. Oxford University Press, 1999. 
Grevenbroeck II, Jan van. "Punishment of a Sorceress". Damned: An Illustrated History of the Devil, por Robert Muchembled, Seuil Chronicle, 2002, p. 108.

Kramer, Heinrich y James Sprenger. The Malleus Maleficarum, traducido por Montague Summers, 1484, Dover Publications, 1971.

Méndez, María Águeda, coordinadora. Catálogo de textos marginados novohispanos: Inquisición siglo XVII, Archivo General de la Nación (México). El Colegio de México, 1997.

Mora, Carmen de. Escritura e identidad criollas. El Carnero, Cautiverio feliz e Infortunios de Alonso Ramirez. Rodopi, 2010.

Muchembled, Robert. Damned: An Illustrated History of the Devil. Seuil Chronicle, 2002.

Rodríguez Freyle, Juan. El Carnero: conquista y descubrimiento del Nuevo Reino de Granada, editado por Jaime Delgado, Dastin Historia, 2000.

Ruiz Tresgallo, Silvia. "Voces silenciadas por la historia: la mujer en la lengua del barroco americano". Hablar y vivir en América. Siglos XVI-XIX, editado por Concepción Company, UNAM y El Colegio Nacional (México) (aceptado para publicación en 2019).

Ruiz Tresgallo, Silvia. "Raza, género y sociedad: la picaresca de la hechicería en 'Un negocio con Juana García’ en $E l$ Carnero de Juan Rodríguez Freyle". América fémina hechiza: la hechicera en la representación de América, The Pennsylvania State University, 2011, pp. 107-199, disertación doctoral, https://etda.libraries.psu.edu/files/fina 1_submissions/5865.

Pupo-Walker, Enrique. "La reconstrucción imaginativa del pasado en El carnero de Rodríguez Freyle”. Nueva Revista de Filología Hispánica, t. 27, n. ${ }^{\circ}$ 2, 1978, pp. 346-358.

Splendiani, Anna María. "El Santo Oficio En Cartagena De Indias: El Delito De Brujeria”. Memoria y Sociedad, vol. 2, n. ${ }^{\circ}$ 3, 1997, pp. 5-20.

Splendiani, Anna María. Cincuenta años de Inquisición el Tribunal de Cartagena de Indias 1610-1660. Vol. 1, Centro Editorial Javeriano, Instituto Colombiano de Cultura Hispánica, 1997.

Splendiani, Anna María, et al., editores. Cincuenta años de Inquisición el Tribunal de Cartagena de Indias 1610-1660. Documentos procedentes del Archivo Histórico Nacional de Madrid (AHMN). Sección Inquisición, Cartagena de Indias, Libro 1020, Años 1610-1637. Vol. 2, Centro Editorial Javeriano / Instituto Colombiano de Cultura Hispánica, 1997.

\section{Notas}

1 Para saber más sobre la relación entre literatura e historia en este texto, recomendados la lectura del ensayo académico de Enrique Pupo-Walker incluido en la bibliografía.

2 Recordemos que es un negra horra, es decir, una mujer que por medio del ahorro ha comprado la libertad.

3 La descripción de este caso recoge la relación de María y su clienta Jacinta. La primera, al leer la buenaventura, afirma que Jacinta tiene un problema con su esposo. Para saber cuál es ese problema y proponer una solución, según explica la clienta, la gitana "llamó al diablo coxuelo y me hiço descalçar en pie e hincar de rodillas, tomó el papel y le metió en vna baçía de agua y le tubo allí un poco de tiempo y le sacó del agua y me lo enseñó” (Caro Baroja 71).

4 Para más información, véase el artículo de Anna María Splendiani "El Santo Oficio En Cartagena De Indias: El Delito De Brujeria" publicado en Memoria y Sociedad, vol. 2, n. ${ }^{\circ} 3$.

5 Estas declaraciones están recogidas en el Libro 1020, dedicado a las causas de la inquisición del tribunal de Cartagena de Indias, guardado en el Archivo Histórico Nacional de Madrid (véase Splendiani et al.).

6 Nuestra interpretación sobre la corrupción existente entre las masculinidades hegemónicas del reino coincide con los comentarios de Carmen Channing Eberhard en su estudio sobre ese caso. Como afirma la investigadora, este territorio colonial evidencia "una profunda crisis moral y administrativa" (47) porque aún se encuentra en consolidación. "Para 1553, el mismo obispo que había condenado a la hoguera a Juana García, escribía a Carlos V indignado por los frailes que vivían en el reino" (47), los cuales practicaban la apostasía y no vivían "en observancia, clausura ni religión [...] las heces y escoria que España deshecha por no poderlos sufrir” (Channing 47). Si sumamos esta carta de Juan de los Barrios a otros documentos e incluso ejemplos propuestos por Rodríguez Freyle en El Carnero, sin duda los varones que habitan el reino no quedan bien parados. 
$7 \quad$ El segundo libro de Cincuenta años de Inquisición en el Tribunal de Cartagena de Indias recoge en el número 17, "En cuerpo con vela en la mano", el caso de Diego Rodríguez Nuñez, un portugués cristiano nuevo que había sido desterrado a Angola por 6 años debido a "siniestras causas" (248). Esta expresión nos da a entender que había realizado actos de hechicería o un pacto con el demonio, motivo que causa su expulsión. Al no haber cumplido esta primera pena y haber sido descubierto en las Indias, se le condena al destierro permanente de las Américas y a cumplir su primera sentencia.

\section{Licencia Creative Commons CC BY 4.0}

Cómo citar: Ruiz Tresgallo, Silvia. "Voces silenciadas por la historia: la hechicera Juana García o la obliteración de la afrodescendencia". Cuadernos de Literatura, vol. 25, 2021, https://doi.org/10.11144/ Javeriana.cl25.vshh 